\title{
BIPA Teacher Education: Meeting the Challenge and Opportunities to Create Qualified Teachers
}

\author{
Paulina Chandrasari Kusuma \\ Atma Jaya Catholic University of Indonesia, Jakarta \\ paulina.cs@atmajaya.ac.id
}

\begin{abstract}
The internationalisation of the Indonesian language has sparked off the new trend in the conduct of Indonesian as a foreign language (commonly known as BIPA) programs in the country and across nations. Vast number of Indonesian language education as well as the increasing interest among non-native speakers to learn Indonesian mark the rising of the importance of the Indonesian language mastery. Unfortunately, this positive situation is not coupled with the sufficiency of qualified BIPA instructors due to, among other factors, lack of BIPA teacher training and education in formal education domain. The intention to tackle the challenges has emerged at the English Department, Atma Jaya Catholic University of Indonesia together with the attempt to renew and develop the curriculum by integrating BIPA education subjects. Taking the ideas of [1] and [2] on the qualification of language teacher and BIPA teacher, respectively as references, a series of activities have been undertaken for the aforementioned purpose. This study, hence, is qualitative by nature and is focused on identifying the extent to which the development of BIPA education curriculum has been conducted. The analysis was done upon documents documenting the process and the documents serving as the products of the curriculum development. The entire process has resulted in the novel graduate profile, description of competencies acquired, the inclusion of BIPA education subjects in the new curriculum, and the provision of modules serving as the main materials for candidates BIPA teacher. This paper, eventually, aims to provide the brief overview of the BIPA education curriculum development embracing its rationale, process and final design of the curriculum at the institution.
\end{abstract}

Keywords: language teacher qualification, BIPA education program, BIPA education curriculum,

\section{PENDAHULUAN}

Maraknya program Bahasa Indonesia bagi Penutur Asing (BIPA) baik di dalam maupun luar negeri menciptakan peluang dan tantangan di banyak bidang yang terkait. Dinyatakan oleh [1] bahwa setidaknya ada tiga aspek peluang yang muncul akibat semakin berkembangnya program BIPA di berbagai institusi pendidikan formal dan non-formal di banyak tempat. Ketiganya aspek tersebut terkait bisnis, sains dan profesi. Program BIPA dianggap bisa menciptakan peluang di bidang bisnis karena merupakan lahan bisnis baru bagi sentra-sentra pendidikan bahasa. BIPA memiliki potensi untuk menjadi bidang ilmu tersendiri, seperti halnya TESOL/TEFL dalam bahasa Inggris. Selain itu, program BIPA membuka peluang adanya 
profesi baru, yaitu guru atau pengajar BIPA. Peluang-peluang yang timbul karena perkembangan program BIPA ternyata dibarengi dengan tantangan-tantangan. Salah satunya adalah tantangan untuk menyiapkan tenaga pengajar BIPA yang berkualifikasi.

Mencetak pengajar BIPA yang memiliki kualifikasi baik dan minimnya jumlah pengajar BIPA yang berpengalaman menjadi tantangan dan hambatan tersendiri yang harus dipikirkan dan dicarikan solusinya demi keberlangsungan kemajuan program BIPA. Beberapa penyebab minimnya jumlah pengajar BIPA yang memenuhi kualifikasi antara lain, (1) belum ada lembaga yang menghasilkan lulusan yang merupakan pengajar BIPA [3]; (2) belum terdefinisikan dengan jelas kualifikasi dan kriteria apa yang dibutuhkan agar seseorang dapat menjadi pengajar BIPA yang efektif yang dapat menjadi acuan pengembangan program-progran pendidikan BIPA (3) masih ada kebingungan dan kerancuan mengenai siapa yang dianggap layak menjadi pengajar BIPA: penutur asli bahasa Indonesia atau orang asing yang telah menguasai bahasa Indonesia? Lulusan pendidikan bahasa atau sastra Indonesia? Lulusan pendidikan bahasa Indonesia atau pendidikan bahasa asing (misalnya bahasa Inggris)? (4) keterbatasan waktu yang dimiliki oleh pengajar BIPA berpengalaman, yang umumnya adalah para dosen, untuk memfokuskan diri pada pengajaran BIPA [3].

Ikhwal belum adanya lembaga pendidikan BIPA yang menghasilkan guru BIPA, [3] mengusulkan, antara lain: pendirian prodi BIPA dan rekonstruksi kurikulum program studi pendidikan bahasa dengan adanya penambahan mata kuliah pendidikan BIPA. Saat ini beberapa lembaga pendidikan formal, terutama lembaga perguruan tinggi atau Lembaga Pendidikan Tenaga Keguruan (LPTK) yang memiliki program studi pendidikan bahasa Indonesia atau bahasa asing sudah menginisiasinya, sebut saja Universitas Negeri Yogyakarta (UNY), Universitas Pendidikan Indonesia (UPI), Universitas Negeri Jakarta (UNJ), dan Universitas Negeri Semarang (UNES). Termotivasi oleh para pendahulunya, Fakultas Pendidikan dan Bahasa Universitas Katolik Indonesia Atma Jaya, khususnya Program Studi Pendidikan Bahasa Inggris (PBI) melakukan hal yang serupa dengan tujuan untuk menangkap peluang mencetak tenaga pengajar BIPA yang berkualitas. Akan tetapi merekonstruksi kurikulum bukanlah hal yang mudah, terutama karena sejatinya PBI mencetak lulusan yang kompeten mengajar bahasa Inggris sebagai bahasa kedua/asing dan bukan bahasa Indonesia sebagai bahasa kedua/asing. Berkaitan dengan hal tersebut di atas, makalah ini disusun berdasarkan beberapa rumusan pertanyaan, yaitu: (1) Apa yang menjadi dasar pemikiran mengintegrasikan pendidikan guru BIPA (yang selanjutnya dalam makalah ini juga akan disebut pendidikan BIPA) di dalam kurikulum PBI? (2) Bagaimana proses persiapan rekonstruksi kurikulum hingga implementasinya dalam pembelajaran dilakukan? (3) Rancangan kurikulum seperti apa yang dianggap 'cukup memadai' untuk membekali mahasiswa FPB UAJ-PBI menjadi pengajar BIPA yang memenuhi kualifikasi yang disyaratkan? Dengan demikian, tulisan ini memiliki beberapa tujuan yang selanjutnya akan dijabarkan di bagian-bagian selanjutnya. Tujuan tersebut dijabarkan sebagai berikut: 1) Mengidentifikasi alasan-alasan atau latar belakang pemikiran dilakukannya rekonstruksi kurikulum PBI dengan menggabungkan mat kuliah pendidikan BIPA, 2) Mendeskripsikan proses pengembangan kurikulum, dan 3) mendeskripsikan rancangan kurikulum beserta perangkatnya: silabus dan modul-modul pembelajaran untuk pendidikan BIPA.

Untuk memperoleh data dan informasi yang diperlukan untuk penyusunan tulisan ini selain dilakukan studi pustaka untuk mendapatkn dasar-dasar teori mengenai kualifikasi pengajar atau guru bahasa kedua dan pendidikan guru bahasa kedua, dilakukan pula kajian terhadap dokumendokumen kurikulum baru PBI. Selain itu penulis melakukan wawancara dengan pimpinan fakultas dan program studi serta mengadakan diskusi dengan tim pengembang kurikulum untuk memperoleh informasi-informasi penting lain yang terkait isu penelitian ini. 
Penulis berharap bahwa tulisan ini dapat memberi kontribusi setidaknya dalam dua hal. Yang pertama, paparan ini memberikan pemahaman yang lebih dalam mengenai kemungkinan dan peluang bagi lembaga pendidikan tenaga kependidikan atau institusi pendidikan lain di bidang pengajaran bahasa untuk mengintegrasikan pendidikan BIPA dalam tujuan dan desain pengembangan program studi. Selanjutnya, paparan dalam makalah ini memberikan gambaran mengenai model desain program pendidikan BIPA bagi institusi pendidikan tenaga kependidikan khususnya pendidikan BIPA.

Pendidikan Guru Bahasa Kedua/Asing (PGBKA) didefinisikan sebagai sebuah jembatan yang menghubungkan disiplin-disipin ilmu akademik di ranah pengajaran bahasa beserta atmosfer kebijakan lokal dan nasional dengan apa yang dikerjakan di dalam kelas, dilakukan melalui individu-individu yang dididik sebagai guru [4]. Dengan kata lain PGBKA harus bisa membantu mengejawantahkan teori-teori ke praktik di kelas dengan memperhatikan kebijakan dan aturan-aturan penyelenggaraannya baik yang bersifat lokal atau institusional maupun nasional.

Menurut [5] program- program PGBKA sangat bervariasi dalam sifat, isi, panjang, dan bahkan dalam dasar-dasar filosofis dan teoretis mereka. Ini sesuai juga dengan kondisi di Indonesia. Pendidikan BIPA di Indonesia ada yang diselenggarakan ada di jenjang S1 dengan menyisipkan mata kuliah-mata kuliah yang relevan, ada yang di jenjang S2 dan menjadi semacam program peminatan. Ada yang diselenggarakan di prodi Pendidikan Bahasa Indonesia, ada pula yang di integrasikan dalam mata kuliah di prodi pendidikan bahasa asing. Terlepas dari beragamnya bentuk penyelenggaraan PGBKA baik di dalam maupun luar Indonesia, [6] mensyaratkan 3 basis pengetahuan yang menjadi komponen-komponen penting, yaiyu: (1) standar isi/konten program pendidikan guru: "What L2 teachers need to know?" (2) aspek pedagogi yang diajarkan dalam program pendidikan guru L2: "How L2 teachers should teach?"; dan (3) desain atau struktur program untuk menyampaikan konten dan pedagogi: "How L2 teachers learn to teach".

Seperti yang telah dikemukakan sebelumya bahwa adanya standar isi, aspek pedagogi dan struktur program merupakan syarat yang harus dipenuhi dalam pelaksanaan PGBKA. Akan tetapi, hingga saat ini belum ada standar kualifikasi pengajar BIPA sehingga standar kompetensi lulusan dari pendidikan BIPA juga belum dapat dirumuskan. Secara umum yang dapat dijadikan pedoman adalah kompetensi atau kualifikasi guru yang diatur dalam Undang-Undang Republik Indonesia nomor 14 Tahun 2005 tentang Guru dan Dosen pasal 1, butir C [7] dan selanjutnya dijelaskan lebih lanjut dalam Peraturan Pemerintah RI nomor 10/2005 tentang Standar Nasional Pendidikan [8]. Disebutkan bahwa seorang guru atau dosen harus menguasai kompetensi kepribadian, pedagogik, profesional dan sosial. Dengan demikian, seorang pengajar BIPA juga diharapkan menguasai keempat kompetensi tersebut dengan baik.

Ada beberapa rumusan yang lebih detail mengenai kualifikasi seorang pengajar bahasa asing/kedua yang dapat dipakai sebagai acuan. [2] mengklasifikasi kompetensi guru bahasa asing/kedua ke dalam enam kelompok, yaitu penguasaan teori pengajaran (theories of teaching), keterampilan mengajar (teaching skills), keterampilan berkomunikasi (communication skills), penguasaan bidang ilmu (subject matter knowledge), keterampilan penalaran pedagogis dan pengambilan keputusan (pedagogical reasoning and decision making), dan pengetahuan kontekstual (contextual knowledge). Pandangan dan komponen kompetensi yang serupa juga dikemukakan [9] yang memberikan label yang berbeda untuk konsep yang sama dengan yang diberikan [2].

Secara khusus deskripsi kualifikasi yang dianggap ideal bagi seorang pengajar BIPA dijabarkan oleh [1]. Pengajar BIPA diharapkan memiliki kemampuan sebagai berikut: (a) menguasai bidang ilmunya, dengan kata lain terampil menggunakan bahasa dalam 4 
keterampilan berbahasa dan memiliki pengetahuan tentang aspek-aspek kebahasaaan (b) memiliki kompetensi pedagogis, terutama terkait dengan pengajaran bahasa sebagai bahasa asing, termasuk juga kemampuan merencanakan, mengimplementasikan dan mengevaluasi program, menerapkan model, menggunakan media yang tepat sesuai dengan karakteristik pemelajar (c) memiliki pengetahuan yang luas, (d) bersikap responsive terhadap terhadap perkembangan ilmu (e) memiliki tanggung jawab dan lapang terhadap kritikan, (f) memiliki kode etik sebagai pengajar BIPA, dan (g) memiliki pengetahuan lintas budaya (cross-cultural understanding).

\section{METODE PENELITIAN}

Penelitian ini merupakan penelitian yang bersift kualitatif. Pengajian yang dilakukan menitik beratkan pada analisis bahan tertulis berupa dokumen-dokumen. Dokumen yang menjadi sumber telaah adalah seluruh catatan tentang penyelenggaraan seluruh proses kegiatan yang dilakukan dalam rangka pengembangan kurikulum dan program, serta dokumen yang merupakan produk dari kegiatan. Dari manuskrip-manuskrip tersebut diidentifikasi tahapantahapan pelaksanaan pengitegrasian kurikulum, latar belakang pemikiran dan teori pengembangan kurikulum, serta dideskripsikan hasil dan produknya. Untuk tujuan tersebut, peneliti mendapatkan ijin khusus dari pihak program studi pendidikan Bahasa Inggris dalam penggunaan dokumen, mengingat bahwa semua doumen tersebut adalah dokumen resmi milik lembaga.

\section{PEMBAHASAN}

\subsection{Dasar Pemikiran Mengintegrasikan Pendidikan BIPA di kurikulum PBI}

Pengintegrasian mata kuliah pendidikan BIPA di kurikulum PBI didasarkan pada lima dasar pemikiran yang dirumuskan di periode regular pengembangan kurikulum program studi atau lebih tepatnya di tahun 2016. Dasar pemikiran yang pertama adalah bahwa tim pengembang kurikulum prodi melihat pendidikan BIPA sebagai sebuah peluang untuk mengembangkan prodi PBI Atma Jaya. Pengetahuan dan keterampilan pendidikan BIPA dipandang akan memberikan tambahan bekal kemampuan dan keterampilan lulusan dalam pengajaran BIPA, maka lulusan prodi PBI akan memiliki lebih banyak pilihan bidang profesi yang akan ditekuninya. Penambahan mata kuliah pendidikan BIPA di kurikulum dianggap mampu menjadi 'poin jual' prodi yang diharapkan mampu menarik minat calon mahasiswa baru. Alasan yang kedua adalah adanya intensi prodi PBI untuk menjadi salah satu institusi/lembaga pendidikan yang menghasilkan lulusan yang merupakan pengajar BIPA sehingga dapat berkontribusi memenuhi kebutuhan pasar yang tinggi akan pengajar BIPA professional dan berkualitas dan memajukan ke-BIPA-an. Pertimbangan selanjutnya berkaitan dengan hasil survey dari alumni PBI yang menunjukkan lebih dari 90\% responden mendukung penambahan rumpun pengetahuan dan keterampilan pengajaran BIPA. Survey ini dilakukan mengawali proses evaluasi dan pengembangan kurikulum prodi yang secara rutin dilakukan dalam periode 5 tahun. Pertimbangan keempat didasarkan pada banyaknya alumni PBI yang berprofesi sebagai pengajar BIPA tetap atau paruh waktu, baik sebagai pengajar mandiri maupun pengajar di sentra-sentra pendidikan, seperti di Satuan Pendidikan Kerjasama (SPK), universitas di dalam dan luar negeri, sentra pendidikan bahasa asing, dan kursus-kursus. Yang menjadi dasar pemikiran terakhir adalah banyaknya alumni PBI yang terpilih menjadi pengajar BIPA di luar negeri melalui program-program yang diselenggarakan dan didanai oleh lembaga atau institusi 
pemerintah negara lain, contohnya: Fullbright Foreign Language Teaching Assistant Program (FLTA) yang dikelola oleh American Indonesian Exchange Foundation (AMINEF) dan Language Assistant Program yang sekarang dikelola oleh Balai Bahasa Perth.

\subsection{Langkah-langkah pengembangan rumpun pengetahuan dan keterampilan pengajaran BIPA di PBI}

Saat ini, implementasi kurikulum PBI yang baru yang telah mengintegrasikan mata kuliah rumpun pendidikan atau pengajaran BIPA telah masuk tahun yang kedua atau semester ketiga. Sebelum akhirnya diterapkan dalam proses pembelajaran, banyak tahapan telah dilalui. Langkah paling awal adalah penetapan dasar pemikiran perubahan atas kurikulum tim pengembang kurikulum (didasarkan pada hasil kajian terhadap potensi dan kontribusinya bagi pengembangan prodi, masukan alumni yang diperoleh dari tracer study, rekomendasi kepalakepala pusat bahasa dan penyelenggara program BIPA dalam forum diskusi terpumpun, dan kebutuhan pasar akan adanya pendidikan guru BIPA). Setelah dasar pemikiran dan pertimbangan-pertimbangan lain disepakati, dirumuskanlah profil lulusan. Selanjutnya, tim menentukan Capaian Pembelajaran Lulusan (CPL) menggunakan profil lulusan PBI sebagai acuan. CPL mencakup empat kompeten kompetensi dasar yang harus dikuasai lulusan setelah menyelesaikan pendidikan mereka, yaitu kompetensi kepribadian, pedagogi, pengetahuan, dan sosial. Tahap selanjutnya adalah penyusunan mata kuliah, termasuk mata kuliah pendidikan BIPA dan dilanjutkan dengan perumusan Capaian Mata Kuliah (CPMK). Dalam CPMK disertakan uraian bobot mata kuliah dan deskripsi mata kuliah. Yang menjadi langkah terakhir dalam proses pengembangan kurikulum adalah pembuatan silabus dan modul-modul yang menjadi buku pegangan dan buku teks bagi mahasiswa.

Sepanjang proses pengintegrasian mata kuliah BIPA, untuk menjamin kualitas kurikulum yang dikembangkan maka dilakukan kajian-kajian dan evaluasi terhadap draf kurikulum oleh para pakar dari dalam dan luar institusi melalui lokakarya dan forum diskusi terpumpun. Khusus untuk mata kuliah pendidikan BIPA, pakar memberikan masukan-masukan yang berkaitan dengan jenis mata kuliah pendidikan BIPA dan isinya, rancangan atau konsep dan isi modulmodul mata kuliah Pendidikan BIPA. Modul-modul pendidikan BIPA, yang disusun oleh para pakar dan pengajar BIPA berpengalaman, disiapkan sebagai buku pegangan dan materi ajar utama bagi mahasiswa. Modul-modul tersebut dikembangkan melalui serangkaian kegiatan. Pertama-tama draf modul disusun oleh tim pengembang modul dengan mengacu pada CPMK yang telah dirumuskan. Draf tersebut kemudian ditinjau dan dievaluasi oleh tim khusus yang terdiri dari para pakar di bidang ke-BIPA-an dan pengajaran BIPA untuk kemudian direvisi. Draf kedua yang merupakan hasil revisi didiskusikan dan dievaluasi kembali oleh pakar dan dimatangkan dalam sebuah forum diskusi terpumpun di mana tim pengembang dan tim evaluasi duduk bersama untuk bertukar pikiran mengani penyempurnaan modul. Butir-butir pemikiran penting yang ditelurkan dalam forum menjadi referensi untuk perbaikan modul-modul lebih lanjut sebelum akhirnya siap digunakan dalam pembelajaran.

\subsection{Deskripsi Kurikulum Pendidikan BIPA PBI}

Secara singkat rancangan kurikulum baru PBI yang teritegrasi dengan pendidikan BIPA memuat poin-poin penting terkait profil lulusan, kompetensi yang dikuasai oleh lulusan, mata kuliah pendidikan BIPA. Dalam profil lulusan dinyatakan bahwa lulusan PBI selain dianggap mampu menjadi pendidik bahasa Inggris, dianggap kompeten menjadi instruktur BIPA di sekolah dan pendidikan informal. Mereka juga memiliki bekal untuk menjadi perancang materi 
dan kurikulum pendidikan kedua bahasa, pengembang bahan ajar bahasa berbasis digital, dan penerjemah pemula. Secara khusus kompetensi pendidikan BIPA di dalam kurikulum PBI dirumuskan sebagai berikut: mahasiswa PBI menguasai tata bahasa dan kosa kata bahasa Indonesia dan pengetahuan mengenai budaya Indonesia dan wawasan ke-BIPA-an untuk tujuan mengembangkan bahan ajar dan kegiatan pembelajaran bahasa Indonesia bagi penutur bahasa asing yang sesuai dengan kebutuhan dan karakteristik pemelajar. Untuk bisa membekali mahasiswa insruktur atau guru BIPA, ditentukanlah lima mata kuliah baru yang merupakan mata kuliah pendidikan BIPA yang terdiri dari: Tata Bahasa Indonesia, Keberagaman Budaya Indonesia dan Multikulturalisme, Metode Pengajaran Bahasa Indonesia sebagai Bahasa Kedua/Asing, Pengembangan Kurikulum dan Materi Pembelajaran BIPA, dan Pengajaran Mikro BIPA dalam Konteks [10].

Mata kuliah Tata Bahasa Indonesia diberikan untuk membekali siswa dengan pengetahuan tentang tata bahasa Indonesia baku yang dibutuhkan dalam pengajaran bahasa Indonesia bagi penutur asing di semua tingkat (BIPA 1-7, mengikuti pemeringkatan dalam Standar Kompetensi Lulusan BIPA [10]). Mata kuliah kedua yaitu, Keberagaman Budaya Indonesia dan Multikulturalisme diarahkan untuk pengayaan pengetahuan mengenai ke-Indonesia-an, yang meliputi politik dan sistem pemerintahan, ekonomi, sosial-budaya, pendidikan, geografis yang mengarah kepada kesamaan pemahaman tentang keanekaragaman budaya Indonesia dan latar belakang budaya peserta didik. Agar mahasiswa mendapatkan pemahan mengenai prinsipprinsip yang mendasari metode pengajaran BIPA dan teknik teknik pengajaran empat keterampilan berbahasa: menyimak, berbicara, membaca dan menulis; dan komponen bahasa maka diberikan mata kuliah Metode Pengajaran Bahasa Indonesia sebagai Bahasa Kedua/Asing. Selanjutnya, pemahaman akan standar kurikulum BIPA yang umum dipakai oleh institusi penyelenggara BIPA dan kemampuan untuk mengembangkan materi pembelajaran bahasa Indonesia bagi penutur asing sesuai dengan standar kurikulum diharapkan dapat diperoleh dan dikuasai melalui mata kuliah Pengembangan Kurikulum dan Materi Pembelajaran BIPA. Mata kuliah Pendidikan BIPA yang terakhir, yaitu Pengajaran Mikro BIPA dalam Konteks secara khusus ditujukan untuk memberikan pengalaman mengajar BIPA melalui kegiatan observasi di kelas-kelas BIPA dan melakukan pengajaran sejawat di dalam kelas. Informasi dan pemahaman atas pelaksanaan dan kondidi pengajaran BIPA di kelas nyata dipergunakan dalam menyusun perencanaan pembelajaran dan penyusunan perangkat pembelajaran yang digunakan dalam pengajaran mikro atau pengajajaran teman sejawat. Setelah itu mahasiswa, diharapkan mampu melakukan refleksi atas kegiatan pembelajaran yang dilakukannya [10].

Jika dikaitkan dengan deskripsi kualifikasi guru [1] dan [2], mata kuliah Tata Bahasa Indonesia dan Keberagaman Budaya Indonesia dan Multikulturalisme merupakan mata kuliah yang ditujukan untuk penguasaan bidang ilmu, sedangkan mata kuliah Metode Pengajaran Bahasa Indonesia sebagai Bahasa Kedua/Asing, Pengembangan Kurikulum dan Materi Pembelajaran BIPA dan Pengajaran Mikro BIPA dalam Konteks diarahkan ke penguasaaan teori pengajaran dan keterampilan mengajar (kompetensi pedagogis).

Kelima mata kuliah Pendidikan BIPA didukung beberapa mata kuliah, diantaranya Pendidikan dalam Konteks Global, Penilaian Pembelajaran, dan Media, Teknologi dalam Pembelajaran, dan Pengembangan Alat Uji Kemampuan Berbahasa yang merupakan mata kuliah-mata kuliah pedagogi umum. Pengetahuan kontekstual dan pengetahuan lintas budaya dikembangkan melalui mata kuliah Pemahaman Lintas Budaya. Untuk kompetensi yang juga esensial bagi calon pengajar BIPA, seperti kompetensi kepribadian dan sosial, pada umumnya diintegrasikan dalam mata kuliah-mata kuliah lain [11]. 


\section{SIMPULAN}

Pengintegrasian mata kuliah BIPA ke dalam kurikulum PBI adalah sebuah upaya awal yang baik yang dapat ditempuh untuk menjawab tantangan dan persoalan mengenai kurangnya tenaga pengajar BIPA berkualitas di dalam dan luar negeri. Hal ini pula yang menjadi salah satu pertimbangan bagi prodi PBI untuk melakukan restrukturisasi kurikulumnya. Namun demikian, kenyataan bahwa belum adanya standar kurikulum resmi menjadikan upaya tersebut kurang maksimal. Oleh karenanya, diperlukan peninjauan dan evaluasi berkala untuk penyempurnaan kurikulum tersebut sehingga semakin sesuai dengan kebutuhan dan mampu membantu mahasiswa menguasai kompetensi-kompetensi penting untuk mengajar BIPA secara optimal.

\section{REFERENCES}

[1] I. M. Sujana, "Program Pembelajaran Bahasa Indonesia," Researchgate, No. August 2012, 2017.

[2] J. C. Richards, "Exploring Teacher Competence In Language Teaching *," Lang. Teach., Vol. 35, No. 4, Pp. 3-7, 2011.

[3] I. Suyitno, Norma Pedagogis Pembelajaran Bahasa Indonesia Untuk Penutur Asing: Deskripsi Teoritis Dan Hasil Kajian Empirirs. Bandung: Reflika Aditama, 2017.

[4] D. Freeman, Educating Second Language Teachers. Oxford: Oxford University Press, 2016.

[5] T. S. C. Farrell, "Second Language Teacher Education And Future Directions," Tesol Encycl. English Lang. Teach., No. 1990, Pp. 1-7, 2018.

[6] K. E. Johnson, Second Language Education: A Sociocultural Perspective. New York: Routledge, 2009.

[7] Republic Of Indonesia, Undang-Undang Republik Indonesia No. 14 Tahun 2005 Tentang Guru Dan Dosen Pasal 1, Butir C. 2005.

[8] Republic Of Indonesia, Peraturan Menteri Pendidikan Dan Kebudayaan Republik Indonesia No. 27 Tahun 2017 Tentang Standar Kompetensi Lulusan Kursus Dan Pelatihan Bidang Bahasa Indonesia Bagi Penutur Asing. Republic Of Indonesia, 2017.

[9] R. R. Day, "Teacher Education," J. Spec. Educ. Technol., Vol. 16, No. 3, Pp. 47-50, 2001.

[10] Program Studi Pendidikan Bahasa Inggris, "Kurikulum Program Studi Pendidikan Bahasa Inggris Tahun 2018,” Jakarta, 2018.

[11] K. Saddhono, "Integrating culture in Indonesian language learning for foreign speakers at Indonesian universities," J. Lang. Lit., vol. 6, no. 2, 2015. 